\title{
doispontos:
}

\section{O Pensamento do Mesmo: entre utopias e heterotopias}

\author{
Cesar Candiotto ${ }^{1}$ \\ ccandiotto@gmail.com \\ Programa de Pós-graduação em Filosofia, Pontifícia Universidade Católica do Paraná (PUCPR), Curitiba, Brasil
}

Resumo: O artigo analisa os limites do "pensamento do Mesmo" no livro As palavras e as coisas. Eles são observáveis na própria estratégia analítica da arqueologia quando são descritos os limiares de descontinuidade entre um e outro espaço de saber. Os limiares indicam um não-lugar irredutível ao modo de ser de uma épistémè específica. Menos ocupada em ordenar identidades e diferenças a partir de estruturas formais, a arqueologia do saber procura estabelecer os limites do pensamento entre os distintos modos de ser da ordem. Trata-se de enfatizar os intervalos nos quais a sintaxe que fixa um lugar comum entre coisas e palavras é desfeito. Ou ainda, sublinhar os pontos de fratura no espaço liso das utopias e sua gramática, quando objetos conceituais, tais como o homem, deixam de ser concebidos como universais. Sugere-se que o livro As palavras e as coisas pode ser pensado como uma modalidade de heterotopia que inquieta certezas e evidências assim como desarma o pensamento de sua pretensão totalizante.

Palavras-chave: arqueologia do saber; heterotopia; homem; épistémè.

\section{The Thought of the Same: between utopias and heterotopias}

\begin{abstract}
The article analyzes the limits of "Thought of the Same" in the book'The Order of Things'. They are observable in their own analytical strategy of archeology when the thresholds of discontinuity between one and the other space of knowledge are described. The thresholds indicate an irreducible non-place to the way of being of a specific episteme. Less busy in ordering identities and differences from formal structures, the archeology of knowledge seeks to establish the limits of thought between the different ways of being from the order. It is to emphasize the intervals in which the syntax which fixes a common place between things and words is undone. Or still, to underline the fracture points in the smooth space of utopias and its grammar, when conceptual objects, such as man, are no longer conceived as universal. It is suggested that the book'The Order of Things' can be thought of as a heterotopy modality that troubles certainties and evidences as well as disarms the thought of its totalizing pretension.
\end{abstract}

Keywords: archeology of knowledge; heterotopia; man; epistémè.

\section{INTRODUÇÃO}

As palavras e as coisas, de Michel Foucault, tem sido uma das grandes referências do pensamento francês contemporâneo. Nessa obra temos o desenvolvimento refinado de um instrumento de análise inaugurado por Foucault nos anos sessenta, que é a arqueologia. Ela certamente não se restringe aos livros e escritos dessa década, assim como a genealogia não teria sido introduzida a partir dos anos 1970, após o suposto fracasso da arqueologia ${ }^{2}$. 
Os livros que constituem o chamado "momento arqueológico" não formam uma unidade homogênea e compacta, não respondem às mesmas problematizações, não realizam os mesmos diagnósticos, de onde a dificuldade de estabelecer entre eles continuidades ou unidades temáticas. Ainda que Foucault lance olhares retrospectivos sobre seu trabalho e tente enquadrar suas principais obras em um fio condutor, esses olhares refletem menos sua preocupação no momento de escrita de cada livro do que a maneira como ele é apropriado quando novas problematizações são suscitadas. Seus livros diferem entre si porque, com eles, não se procura colocar no papel um pensamento já acabado e definido. Pela atividade da escritura pretende-se fazer uma experimentação filosófica para deixar de pensar aquilo que antes se havia pensado, romper com os conhecimentos já elaborados e que conduzem às certezas, realizar enfim um exercício do pensamento que leve a um descaminho daquele que conhece.

Em cada momento de seu trabalho, é realizada uma história das problematizações e não uma história das soluções. Embora o neologismo "problematização" tenha aparecido tardiamente em sua investigação, no curso Segurança, Território, População (1978), no prefácio dos dois últimos volumes de História da sexualidade (1984) e em diversas entrevistas nos anos 1980, ele pode ser indiretamente aplicado ao conjunto de seu pensamento. Esse conceito recobre o próprio trabalho do pensamento crítico, no sentido de que esse pensamento objetiva inquietar as certezas e adotar uma atitude de recuo relativamente às naturalizações sociais pelo viés da acontecimentalização da história.

Acontecimentalizar a história envolve delimitar um conjunto de conceitos e sua descrição no momento em que foram elevados à condição de objetos para o saber. Trata-se do uso específico do trabalho crítico para identificar por que algo que, em um momento da história, não é problemático para o pensamento, em outro se torna objeto a ser pensado seja pela relação estabelecida entre os saberes, seja pela articulação entre técnicas de saber e relações de poder.

A análise arqueológica, principalmente a que vemos em As palavras e as coisas, considera cada época uma configuração espacial de saber que dispõe de um campo de problematização marcado pela raridade. Não se pode buscar a solução para os problemas que emergem em nossa configuração histórica em outra configuração do saber, pois já não se tratam dos mesmos problemas e do mesmo espaço. Contudo, a descrição de outro espaço de saber impõe uma marca para o diagnóstico do presente. Essa marca não denota uma linha de continuidade, mas a possibilidade de uma descontinuidade que nos separa da geografia do passado e suas coerências. $O$ efeito dessa marca é o estranhamento em relação às coerências tornadas habituais em nossa própria época. A problematização do pensamento exige a meticulosa e monótona pesquisa dos arquivos empoeirados de outras camadas de saber. Sem a diferença entre o que nomeamos e pensamos na configuração do presente e aquelas a partir das quais já não podemos mais nomear e pensar, não saberíamos por que nos tornamos quem somos, ou ainda, não sentiríamos um desconforto sobre as coerências em torno daquilo que tornamos natural.

No Prefácio de As palavras e as coisas é explícito o propósito de estudar as familiaridades do pensamento, suas identidades e diferenças, seus sistemas ordenadores de compreensão e a operacionalidade de seus códigos culturais entre os renascentistas, os clássicos (entenda-se Idade clássica) e os modernos. Porém, a tese mais audaz do livro - e que buscamos ressaltar nesse artigo - não é a descrição das familiaridades ordenadas do pensamento e sim a ideia de que inexiste uma maneira única ou progressiva de ordenar os saberes que desembocaria nas ciências modernas e, particularmente, nas chamadas ciências do homem. Se não existe um único modo de ordená-los é porque cada época somente pode pensá-los e apreendê-los a partir de sua própria problematização. 


\section{AS METÁFORAS ESPACIAIS E A DESORDEM DOS LIMIARES ARQUEOLÓGICOS}

Em As palavras e as coisas a existência de diferentes modos de ser, ordenar e apreender as coisas e as palavras e sua mútua relação não é dada pela continuidade da razão e sua temporalidade, mas pelas descontinuidades dos chamados campos arqueológicos ou espaços de saber na história da cultura ocidental. Elas provocam desconforto quando se detêm em outros espaços de saber, principalmente o de nosso passado mais próximo com suas aproximações bizarras e similitudes quase incompreensíveis. $\mathrm{O}$ desconforto ocorre porque cada espaço do saber tem uma gramática específica para relacionar as palavras e as coisas, dificultando supor que um desses espaços seja a evolução dos anteriores ou a preparação daquele que o segue. Esses espaços estão, a nosso ver, na raiz da visão descontínua da história na arqueologia. De modo mais evidente, em Nascimento da clínica e As palavras e as coisas, a arqueologia privilegia a concepção de espaço sobre a de tempo ${ }^{4}$ (ou, no limite, espacializa o próprio tempo) a fim de tomar distância de uma história continuísta cujo motor seria a atividade do sujeito sintético e doador de sentido.

O espaço de ordem opera ao modo de um transcendental histórico que informa os saberes responsáveis pela formação dos objetos e pela posição dos sujeitos. Na carta de Foucault ao artigo de Michel Amiot, "Le relativisme culturaliste de Michel Foucault", é ressaltada essa relação a partir de "metáforas espaciais". No espaço renascentista do século XVI, a "esfera" denota a circularidade do saber no momento em que o conhecimento dos seres, das coisas e das palavras é apresentado em sua semelhança com Deus. O "quadro" das identidades e diferenças, próprio das classificações, configura o espaço clássico dos séculos XVII e XVIII, assim como o "quadrilátero" da linguagem retrata a relação entre o saber e o espaço moderno do século XIX. Finalmente, o "triedro" do pensamento contemporâneo a partir de 1950, descrito no capítulo X, é utilizado para mostrar a correlação entre as estruturas científicas entre as quais se constituíram as ciências do homem 5 . Temos, portanto, uma "con-figuração" que indica o modo de ser da ordem, ou ainda, uma relação específica entre saber e espaço. A prioridade do espaço e suas decalagens sobre o tempo contínuo é constitutiva do escopo de elaboração de uma história da transformação dos saberes e seu valor analítico e descritivo diante de uma história da evolução do conhecimento. São as transformações de um espaço A a um espaço B “[...] que servem de regra a uma descontinuidade empírica” (FOUCAULT, 2009, p. 138). Portanto, não se trata de uma descontinuidade sem regra.

Em um sentido amplo e genérico, o espaço de ordem é tudo o que em cada camada de saber permite nomear, pensar e falar, sem que cause estranheza e estupor a seus contemporâneos. $O$ conceito que designa essa possibilidade é a épistémè, considerado o princípio ordenador do modo de apreensão dos saberes empíricos e filosóficos. A seu respeito, lê-se no livro de 1966: “[...] numa cultura e num dado momento, nunca há mais que uma épistémè, que define as condições de possibilidade de todo saber. Tanto aquele que se manifesta numa teoria quanto aquele que é silenciosamente investido numa prática". (FOUCAULT, 1966, p. 179) ${ }^{6}$.

Dessa passagem tem-se a impressão que a épistémè de uma época seja uma categoria totalizante. A leitura atenta do livro, contudo, evita designá-la como totalidade cultural. Vale lembrar que no subtítulo da edição francesa adverte-se que se trata somente de "uma arqueologia das ciências humanas" como se lida com as percepções empíricas e a maneira como as teorias científicas e as reflexões filosóficas as concebem. Percepções e concepções cujas marcas descontínuas confluem nas ciências do homem. O alcance das épistémès não é estendido a todos os domínios, mas somente àqueles cuja formação e transformação torna possível o surgimento do homem como objeto a ser pensado. 
No texto Resposta a uma questão, a épistémè é identificada como "campo epistemológico", "espaço de dispersão", “campo aberto de relações”, expressões todas elas espaciais que se referem a um jogo simultâneo de descontinuidades. Ainda: ela “[...] não é um estado geral da razão; é uma relação complexa de decalagens sucessivas.” (FOUCAULT, 1994a, p. 676-677). Ela não é um sistema, antes faz proliferarem os sistemas, o conjunto de discursos, os jogos de regras, os feixes de relações. Enfim, ela é um conjunto de relações entre os diferentes domínios empíricos e reflexivos de um determinado campo epistêmico que os torna apreensíveis ao saber. Trata-se de um espaço de dispersão histórico ou algo que configura um espaço de saber determinado.

A épistémè não é também uma categoria epistemológica. Ela toma distância da afirmação de uma continuidade progressiva da racionalidade em busca de sua cientificidade. Sua descrição histórica não depende de uma vontade consciente de racionalização ou da afirmação livre e soberana de uma razão liberta dos preconceitos do passado. Foucault não nega a razão, somente salienta que seu suposto progresso ou sua quase-continuidade é o efeito de superfície de subsolos nos quais prevalecem os sistemas de regularidades entre os saberes. Após longos períodos, esses sistemas sofrem abalos e rupturas, levando à reacomodação de camadas tectônicas que desaguam em um novo espaço de saber ${ }^{8}$ no qual é possível descortinar outro sistema de regularidades.

Eis a imagem adequada de uma diferença expressiva apontada pela arqueologia: de um lado, nos efeitos de superfície de cada espaço de saber, o que se vê são os conflitos de opiniões, as várias correntes de pensamento, as maneiras diferentes de apreensão do empírico, a continuidade da razão rumo à sua verdade. Mas, de outro lado, o jogo de relações que permite esses efeitos de superfície encontra-se em um subsolo, o qual, entre um e outro espaço do saber, é abalado pela instauração de um novo jogo de relações e suas regras.

Nesse estudo procuramos enfatizar não tanto os sistemas de regularidades dos saberes e sua história mas sobretudo os limites entre uma e outra épistémè, a fim de destacar, a partir deles, a impossibilidade de pensar os mesmos objetos e, portanto, sua raridade entre os diferentes espaços de saber. Esses limites são apreensíveis quando ocorre uma alteração profunda no modo de ser das coisas e da ordem, quer dizer, quando os objetos de saber deixam de ser objetiváveis, quando as coisas às quais habituamos a nomeá-las deixam de ser nomeáveis; ou ainda, quando não podemos falar da mesma maneira a respeito dos mesmos objetos e dos mesmos conceitos. Embora as palavras empregadas entre um e outro espaço de saber possam ser as mesmas, elas já não designam as mesmas coisas, não têm o mesmo sentido, deixam de ser organizadas de igual maneira. As descontinuidades no modo de ser da ordem instauram assim uma desordem, rompendo com a suposta ideia de continuidade.

Aquilo que Foucault propôs chamar de história do Mesmo para designar o recorte de As palavras e as coisas deve ser considerado com cautela. Se esta história do Mesmo é apreensível durante períodos de longa duração mediante a identificação de uma sincronia entre os saberes, o aspecto mais problemático e ao mesmo tempo mais instigante deste livro são os limiares nos quais aquilo a ser recolhido por identidades e distinguido por marcas, deixa de ser possível. É o caso dos dois limiares de descontinuidade no saber ocidental europeu: um que inaugura a Idade clássica, em meados do século XVII, e outro que marca o nascimento de nossa Modernidade, na curva do século XVIII para o século XIX.

Nesses limiares de descontinuidade as distribuições das palavras e coisas deixam de ser delineadas no espaço claro e definido de apreensão dos saberes, seja pela experiência do empírico, seja pelas teorias científicas e reflexões filosóficas com seus objetos de conhecimento. O que se tem é um espaço ainda impensável no qual se entrevê a “[...] experiência nua da ordem e de seus modos de ser” (FOUCAULT, 1966, p. 12-13), uma espécie de região mediana menos clara, mais obtusa. Esse campo epistemológico é um impensado, um não-lugar que permite tanto desordenar uma sintaxe epocal que mantém juntas palavras e coisas, quanto 
reordená-las a partir de uma nova configuração, de uma nova disposição espacial. O limiar que separa um espaço de saber e o que lhe segue oferece ao pensamento outro modo de ser e de ordenar coisas e palavras, de modo que alguns objetos conceituais desaparecem dando origem a outros.

\section{O DESVIO DA CAUSALIDADE HISTÓRICA E SEUS EFEITOS DE SUBJETIVAÇÃO}

A inquietação de alguns filósofos e historiadores logo após a publicação de As Palavras e as coisas, dentre eles Sartre, concentra-se em torno da questão da causalidade e da história. Parece-lhes impossível descrever limiares de descontinuidade sem apelar para a causalidade, identificável sobretudo na práxis dos homens ${ }^{10}$. A descrição arqueológica é acusada de a-histórica pois superpõe camadas sedimentares. Essa história chega a ser equiparada a uma "geologia" (Cf. SARTRE, 2009, p. 76). Por certo, metáforas geológicas e sísmicas como "erosão" (FOUCAULT, 1966, p. 64), "camada", "abalo" (FOUCAULT, 1966, p. 229) são frequentemente utilizadas. Não obstante, o uso desses termos pretende tão-somente destacar os desníveis pelos quais passou a cultura ocidental europeia no domínio dos saberes do século XVI ao século XX.

Em As palavras e as coisas mostra-se a descrição de transformações que, em si mesmas, não recorrem a uma causalidade específica. Na perspectiva arqueológica, as explicações tradicionais como espírito de época, mudanças tecnológicas ou sociais, influências de toda espécie são consideradas "mais mágicas do que efetivas." (FOUCAULT, 1994b, p. 11). Por detrás da defesa da causalidade está implícita a continuidade na história e a unidade do sujeito.

O estudo da formação das camadas discursivas aponta para transformações que não intervêm no mesmo nível, não progridem no mesmo ritmo e não obedecem as mesmas leis. O modo pelo qual no interior de uma formação discursiva novas proposições sejam elaboradas, novos fatos sejam isolados e novos conceitos sejam forjados não pode ser confundido com o aparecimento de novos campos de estudo. São antes as redistribuições que modificam a forma geral de uma ciência e suas relações com outros domínios do saber. Essa é uma das razões pelas quais as descontinuidades arqueológicas não têm como causa o gênio de um indivíduo, o espírito coletivo ou a fecundidade de uma descoberta. Elas questionam portanto um certo tipo de conceber a história, mas não a própria história. Se elas são por vezes "enigmáticas" (FOUCAULT, 1966, p. 229), suscetíveis do acaso e do impensado, é justamente porque eles são constitutivos da prática histórica; não talvez pela perspectiva de como a razão filosófica absorve a história, mas pela maneira como Foucault a pratica. Foi preciso então sair daquela razão, descender à singularidade do modo de ser das palavras, dos seres e dos objetos.

A despeito disso, Foucault reconhece a dificuldade do estabelecimento do estatuto das transformações arqueológicas. Admite que a divisão entre uma e outra época pode não passar muitas vezes de um "corte arbitrário" (FOUCAULT, 1966, p. 64) em meio a um conjunto movediço. Se as continuidades sincrônicas apresentam um esforço de sistematização formal e coerência estrutural, as descontinuidades espaciais apontam para experimentações de "dessistematização" e desestabilização de cada épistémè ${ }^{11}$.

Como passar de um feixe a outro de simultaneidades discursivas sem que haja uma explicação causal ou uma análise em termos de superação de certos elementos internos que possibilitam a transformação? Uma das respostas consiste em dizer que a abertura profunda na camada de simultaneidades de um espaço de saber não pode ser "explicada" univocamente (Cf. FOUCAULT, 1966, p. 229). Está-se diante de um acontecimento radical que se reparte por toda a superfície do saber e do qual a arqueologia tenta descrever, passo a passo, seus abalos. Mais do que investigar a causa da transformação das relações, o acontecimento arqueológico demarca os efeitos de suas descontinuidades, rompendo com a linearidade do par causa/ efeito ${ }^{12}$.

Eis um instrumento de análise que toma distância não somente da teleologia positivista e seu mito do progresso, mas também da explicação dialética pela qual se supera o anterior, conservando-o. (Cf. CANGUILHEM, 
1970, p. 127). Se a coerência de um espaço de saber é interna, somente um elemento que lhe é estranho pode recusá-la, apenas uma "erosão que vem de fora" (FOUCAULT, 1966, p. 64) dá a entender como, de modo escalonado ou bruscamente, deixa de ser possível pensar um pensamento e inaugurar um pensamento novo. A despeito dessa expressão enigmática, acredito que o advérbio "fora", nesse contexto específico, deva ser entendido como o não-lugar situado no limiar entre um e outro espaço de saber e que, no entanto, não se identifica com nenhum deles. Portanto, um não-lugar no interior da própria história.

Entende-se nesse sentido porque a arché, que constitui o termo arqueologia, não visa primeiramente detectar a causa das transformações, mas principalmente descrever seus efeitos, seus estrondos. Ou ainda, ela não pretende apresentar entre um e outro momento histórico uma causa unívoca mas um espaço de dispersão no qual diversos elementos concorrem na mudança do jogo de regras e sua regularidade. Esse espaço de dispersão pode ser pensado como a possibilidade da introdução de um impensado na história e conjecturado como um dos efeitos das descontinuidades arqueológicas.

O pensamento tem uma história e, paradoxalmente, ela jamais pode ser por ele contornada, reduzida, absorvida, enfim, anulada. Esse paradoxo pode ser exemplificado pela relação entre a história e o pensamento filosófico. Por certo, a filosofia sempre esteve condicionada por um espaço que a limita, que é sua história. Na Modernidade, a história não pode ser contornada totalmente pela filosofia, como parecia ser pretensão desta última desde o mundo antigo. O caráter incontornável da história pela filosofia na modernidade é deduzido dos efeitos das descontinuidades arqueológicas. Deriva disso que a tarefa da filosofia deixa de ser compreender a totalidade do histórico ou constituir a história. A filosofia deve antes entender-se a si mesma constituindo-se nas histórias regionais, em meio às histórias vida, do trabalho e da linguagem. Assim também ocorre nas descrições arqueológicas da loucura e da doença, ou ainda nos estudos arqueogenealógicos da penalidade e da sexualidade.

Outro efeito produzido pelas descontinuidades arqueológicas é o desconforto diante das coerências estabelecidas entre saberes e códigos culturais cujo campo arqueológico é diferente do nosso. Quando sentimos um mal-estar em relação àquilo que para os clássicos era coerente, nós mesmos é que somos transformados por essa descoberta. Como sublinha Michel de Certeau, no artigo Les sciences humaines et la mort de l'homme: "[...] a relação com os outros, modificada pela percepção desse desnivelamento cultural, transforma nossa relação conosco mesmos. O solo de nossas seguranças oscila à medida que se desvela $\mathrm{o}$ fato de não mais poder pensar um pensamento de ontem" (CERTEAU, 2009, p. 186).

No livro de 1966, mas também em outros como Nascimento da clínica e os dois últimos volumes da História da sexualidade, são privilegiados os limites do pensamento daquilo que o separa de seus espaços de ordem anteriores. O pensamento "tem uma idade e uma geografia" e as descontinuidades na ordem do saber, observadas em meados do século XVII e no final do século XVIII, abalam quaisquer familiaridades. Os limiares arqueológicos descritos em As palavras e as coisas operam efeitos análogos à classificação da enciclopédia de Borges, retratada no "Prefácio", seja o riso diante de uma ordenação esdrúxula e sem sentido, seja um desconforto difícil de ser vencido. Com efeito, a desordem provocada pelos limiares de descontinuidade

[...] faz cintilar os fragmentos de um grande número de ordens possíveis na dimensão, sem lei nem geometria, do heteróclito; e importa entender esta palavra no sentido mais próximo de sua etimologia: as coisas aí são 'deitadas', 'colocadas', 'dispostas' em lugares a tal ponto diferentes, que é impossível encontrar-lhes um espaço de acolhimento, definir por baixo de umas e outras um lugar-comum. (FOUCAULT, 1966, p. 9).

A partir do não-lugar comum entre clássicos e modernos pode ser entendido o lugar do homem, como objeto conceitual por excelência, em As palavras e as coisas. Pela descrição arqueológica de sua ausência no quadro clássico das identidades e diferenças é que se compreende seu lugar na ordem do saber moderna 


\section{O LUGAR DO HOMEM A PARTIR DOS LIMITES DA REPRESENTAÇÃO}

Da problematização dos limites históricos mediante suas diferentes configurações espaciais é que são delimitadas as condições de possibilidade da emergência do homem como objeto a ser pensado. Por certo, problematizar o pensamento não consiste somente em analisar seus limites, mas também suas possibilidade históricas de emergência. Como sublinha Foucault em uma passagem particularmente importante, em entrevista de 1984: "O trabalho do pensamento não é denunciar o mal que habitaria secretamente tudo o que existe, mas pressentir o perigo que ameaça em tudo aquilo que é habitual, e de tornar problemático tudo aquilo que é sólido". (FOUCAULT, 1994c, p. 612).

Ora, algo sólido no pensamento ocidental, como "a mais velha busca desde Sócrates" (FOUCAULT, 1966, p. 15), é a evidência do conhecimento do homem. A partir das descontinuidades arqueológicas é advertido que ele não existiu sempre como objeto a ser problematizado pelo pensamento. Seria impossível definir um lugar-comum entre aquele ocupado por ele na ordem do saber moderno e todos os outros nos quais ele não assentou seu trono e assegurou sua soberania. Mesmo que esse conceito existisse antes da Modernidade, ele não designava a mesma coisa, pois o espaço de saber que assegurava a sintaxe entre as palavras e as coisas não era a mesma. O que havia, por exemplo, na Idade clássica eram os signos, a relação entre significante e significado pelo crivo da representação, sem a intermediação do homem. Este era somente um nó na cadeia das representações; imperfeição finita situada, não poucas vezes, ao lado de outros seres e quase sempre marcado pela dimensão negativa do pecado.

A lição da arqueologia do saber é que o homem, normalmente concebido pelas modernas filosofias como sujeito doador de sentido (sentido este que teria sido descoberto pela fenomenologia quanto ela identifica um transcendental latente em Descartes) e como objeto para as ciências humanas, não é tão sólido como se imagina, mas constituído nos condicionamentos de sua própria historicidade em um espaço de saber finito. Causa estranheza pensar, por um lado, que entre renascentistas e clássicos o que se tem não é o resplandecer do humanismo e do racionalismo acompanhados da figura do homem de razão como constituidor das palavras e das coisas; homem esse normalmente apresentado pela história das ideias como alguém que nasce de novo a partir dos antigos ideais greco-romanos, adormecidos pelo pensamento teológico medieval. Não deixa de ser ameaçador, por outro lado, quando, desde na segunda metade do século XX, a semiologia, a etnologia, a antropologia estrutural, a linguística e a psicanálise lacaniana, situadas no limiar de uma nova descontinuidade arqueológica, apresentam a centralidade do implícito, do impensado, do discurso, do desejo, tornando ambíguas as noções de consciência de si, de cogito e de origem.

O estranhamento em relação a um espaço de saber que já não é o nosso e a ameaça dos sinais procedentes de um espaço de saber que está em vias de se configurar demarcam o limite de nosso pensamento: seja a dificuldade de se imaginar no interior de códigos culturais, teorias científicas e reflexões filosóficas que se compreendam a partir de uma cadeia representativa e da ausência da figura do homem; seja o temor da eventual mudança de uma disposição arqueológica cuja ordenação descentraliza a forma-homem da Modernidade.

\section{O SONO ANTROPOLÓGICO}

O prestígio do homem moderno está associado a uma teleologia da razão e foi dela que brotaram, escreve Foucault, “[...] as quimeras dos novos humanismos, todas as facilidades de uma 'antropologia', entendida como reflexão geral, meio positiva, meio filosófica, sobre o homem" (FOUCAULT, 1966, p. 15). Por certo, os humanismos ignoram os limites de nosso pensamento e de uma antropologia cuja matriz não é nem 
empírica nem transcendental, mas ambígua pois faz da finitude empírica do homem o fundamento de todo conhecimento. Talvez os humanismos modernos possam ser situados como uma grande narrativa que ignora a ordem a partir da qual se narra, ao modo de uma fábula. Essa ordem não é do nível de um fundamento a-histórico, mas de um princípio ordenador, ele mesmo finito; ela é aquela do espaço volumoso e espesso da História e sua disposição antropológica moderna cuja instauração ocorreu a partir dos limites e abalos do espaço transparente clássico da Representação. A disposição antropológica, a partir da qual foi possível o homem como objeto de conhecimento e sujeito constituinte, é datada, finita e, portanto, não pode servir de fundamento para um objeto, também ele, frágil, movediço, instável.

Se a filosofia moderna se tornou praticamente uma antropologia, se as ciências humanas demandam um homem verdadeiro como seu fundamento, quanto à arqueologia do saber, ela não pretende negar a antropologia mas colocá-la em seu devido lugar. A Antropologia somente é apreensível pela disposição arqueológica de um espaço específico de saber, que é o Ocidental moderno. Por isso, ela tem somente valor de indicação, jamais de fundamento. Como acentuam Jorge Dávila e Frédéric Gros (DÁVILA; GROS, 1998, p. 56): "As ciências humanas podem muito bem continuar permanecendo inscritas em um marco antropológico que, no entanto, não pode cumprir a função de fundamento, posto que, em toda a sua extensão, ele não é mais que um momento histórico".

À diferença de sua tese complementar sobre a Antropologia de um ponto de vista pragmático de Kant, em As palavras e as coisas a Antropologia é concebida como um momento histórico dos saberes e não como o fundamento de um homem verdadeiro. Embora os espaços de saber não tivessem sido introduzidos em 1961, já fora demonstrado nessa tese que, para Kant, a Antropologia, na condição de conhecimento empírico do homem, não dispõe de um solo ontológico próprio. Na verdade, ela é somente o momento de passagem, a mediação entre o Eu puro transcendental das Críticas (que define as condições lógicas de conhecimento, tomadas na atividade sintética de um ego a priori) e o fundamental (que define a estrutura de uma finitude no mundo). (Cf. DÁVILA; GROS, 1998). Nesse sentido, na tese complementar tem-se a possibilidade de identificar já em Kant um transcendental-fundamental, para além do transcendental puro das sínteses a priori.

Em 1966, não é retomado esse viés do fundamental definido pela estrutura originária da finitude; opta-se antes "[...] por um fundamental de uma estrutura histórica determinada como momento" (DÁVILA; GROS, 1998, p. 41). Foucault acontecimentaliza o fundamental. Essa estrutura histórica (ou transcendental histórico) pode ser pensada como o não-lugar da desordem que ordena os espaços de saber de cada época. Por isso a Antropologia não é uma região ontologicamente autônoma ou o fundamento das ciências do homem. Ela não pode ser fundamento porque é apreensível somente no espaço de saber da História, e em nenhum outro. Igualmente o homem, seu objeto, é desprovido de uma verdade originária. Inexiste um homem verdadeiro ou autêntico que dá sentido ao mundo e à experiência, posto que ele, como acontecimento, nasce entre os saberes empíricos modernos " [...] nada mais que uma certa brecha na ordem das coisas, uma configuração, em todo o caso, desenhada pela disposição nova que ele assumiu recentemente no saber" (FOUCAULT, 1966, p. 15). Mas, se esta disposição vier a se transformar em outro limiar de descontinuidade, é essa figura que desvaneceria como "na orla do mar, um rosto de areia". (FOUCAULT, 1966, p. 398).

\section{CONSIDERAÇÕES FINAIS}

Como foi visto no decorrer desse estudo, o pensamento de Foucault opera por problematizações. Dentre outros significados, problematizar é mostrar quando algo se torna um objeto para o pensamento. E esse "quando" é o momento em que o lugar-comum entre coisas e palavras é desfeito, em que os diferentes 
objetos já não têm sentido sobre o mesmo quadro de identidades e diferenças, e o espaço a partir do qual pensamos deixa de ser o mesmo. O que a filosofia moderna e as ciências do homem parecem ter deixado de lado são as condições e possibilidades históricas de nosso pensamento, negligenciando assim os limites que nos impedem pensar a partir de outro espaço de saber. Elas preferiram as facilidades do tempo linear e do progresso da razão; não prestaram atenção aos limiares de descontinuidade e à falta de fundamento dos universais antropológicos. Nesse sentido é que as ciências humanas e, até mesmo, boa parte das chamadas filosofias do sujeito, navegam no espaço liso da utopia.

Se o livro As palavras e as coisas surgiu do riso provocado pela leitura dessa bizarra ordenação da Enciclopédia chinesa de Borges é porque Foucault não pretende compactuar com esses lugares-comuns dos universais antropológicos das histórias continuístas. Os limiares de descontinuidade, os não-lugares que eles instauram - e que Foucault procura destacar - rompem com a solidez e as evidências das utopias modernas a respeito do homem.

Escreve Foucault (1966, p. 9-10):

\begin{abstract}
As utopias consolam: é que, se elas não têm lugar real, desabrocham, contudo, num espaço maravilhoso e liso; abrem cidades com vastas avenidas, jardins bem plantados, regiões fáceis, ainda que o acesso a elas seja quimérico. As heterotopias inquietam, sem dúvida porque solapam secretamente a linguagem, porque impedem de nomear isto e aquilo, porque fracionam os nomes comuns ou os emaranham, porque arruínam de antemão a 'sintaxe', e não somente aquela que constrói frases - aquela, menos manifesta, que autoriza 'manter juntos' (ao lado e em frente umas das outras) as palavras e as coisas. Eis por que as utopias permitem as fábulas e os discursos: situam-se na linha reta da linguagem, na dimensão fundamental da fábula; as heterotopias [...] dessecam o propósito, estancam as palavras nelas próprias, contestam, desde a raiz, toda possibilidade de gramática; desfazem os mitos e imprimem esterilidade ao lirismo das frases.
\end{abstract}

Pensar que existe um lugar-comum entre o homem moderno e o homem dos renascentistas e clássicos é da ordem da utopia; é imaginar uma continuidade entre diferentes espaços. Nesse sentido, contra todas as utopias em torno do homem e dos universais antropológicos que o atribuem um estatuto de verdade, $\mathrm{o}$ livro As palavras e as coisas descreve a quimera desse lugar comum, e ao fazer isso, ele salienta a heterotopia entre palavras e coisas, entre o que designava a natureza humana entre os clássicos e o que passa a referir o acontecimento do nascimento moderno do homem.

\title{
NOTAS
}

1. Bolsista de Produtividade em Pesquisa do CNPq - nível 2.

2. A tese do fracasso da arqueologia é proposta por Dreyfus e Rabinow (1995).

3. Foucault destaca no livro de 1963: "Este livro trata do espaço, da linguagem e da morte; trata do olhar" (FOUCAULT, 1963, p. V). Em vez de mostrar o progresso das teorias e práticas médicas, a arqueologia privilegiou as formas temporais e espaciais do olhar médico, configuradas no papel dos sentidos nas diferentes estruturas perceptivas, nas concepção de mudanças da doença, da morte e da vida.

4. A centralidade do espaço em Michel Foucault tem na filosofia de Bergson uma de suas principais inspirações ou, pelo menos, ela surge de uma discordância em relação a ele. Encontramos essa posição na Conferência "Linguagem e literatura”, de 1964. Segundo a tradição ocidental, pelo menos a que vai de Herder a Heidegger, é na linguagem que o tempo se manifesta a si mesmo e, além disso, vai se tornar consciente de si mesmo como história. Bergson, pelo contrário, afirmou ser a linguagem não tempo, mas espaço. "O problema é que ele tirou disso uma consequência negativa, ao dizer que se a linguagem era espaço e não tempo, pior para ela. E como o essencial da filosofia, que é linguagem, era pensar o tempo, ele tirou essas duas conclusões negativas: primeiro, que a filosofia deveria se afastar do 
espaço e da linguagem para poder pensar melhor o tempo; segundo, que, para poder pensar e expressar o tempo, era necessário dispensar a linguagem ou se desembaraçar daquilo que a linguagem poderia ter de pesadamente espacial. E para neutralizar esses poderes, essa natureza, esse destino espacial da linguagem, seria preciso jogar a linguagem contra ela mesma, utilizar, frente às palavras, outras palavras, contra-palavras”. (FOUCAULT, 2001, p. 167-168).

5. Foucault pretende mostrar como a espacialização está implicada por modos de discursividade: “a Semelhança implicando a esfera; as diferenças, o quadro”. Se a figura da esfera é facilmente identificável entre os renascentistas, assim como o quadro entre os clássicos, no entanto, a proposição do triedro dos saberes é uma invenção dele. Com isso, Foucault não pretende propor uma espacialização inerente ao saber moderno, mas "facilitar a descrição das relações entre diversos domínios científicos, tais como eles se atam no século XIX”. (FOUCAULT, 2009, p. 138).

6. A partir dos debates suscitados por ocasião da publicação de seu livro, a partir de 1969 Foucault utiliza cada vez menos o conceito de épistémè e passa a empregar o conceito de "prática” para se referir ao nível discursivo e ao nível não-discursivo, dando a entender que toda teoria é uma prática.

7. Esse subtítulo não consta na edição brasileira.

8. Ela não é também uma categoria epistemológica porque não procura estabelecer as condições de verdade de um conceito e sim a descrição das condições de existência dos enunciados, justamente daqueles relacionados às possibilidades e limites de uma ciência do homem. Nesse sentido é que a épistémè não é uma categoria totalizante, e sim um conceito que remete a uma análise estritamente regional (Cf. MACHADO, 1988, p. 15-32).

9. Apresentamos esse objeto de pesquisa em outro estudo. Cf. Candiotto (2009).

10. Sartre é enfático, neste ponto: "Um historiador, hoje, pode não ser comunista; mas ele sabe que não podemos escrever a história séria sem colocar em primeiro plano os elementos materiais da vida dos homens, as relações de produção, a práxis." (SARTRE, 2009, p. 77).

11. Philippe Sabot, em seu livro Le Même et l'Ordre sugere que “[...] as análises sistematizantes que Foucault propõe em Les mots et les choses não devem ser tomadas como esforços de totalização que forçam a coerência interna de cada épistémè para se conformar a alguma ideologia estruturalista; elas comportam sempre um momento de dessistematização que reconduz as descrições propostas à sua função propriamente crítica no seio da empresa global da obra” (SABOT, 2015, p. 12, tradução nossa).

12. Como adverte Judith Revel: “Desse modo, é absurdo para Foucault pensar o acontecimento somente nos quadros de um determinismo causal (posto que este tem como elemento específico esfacelar a relação linear causa/efeito e nela introduzir uma descontinuidade), mas, inversamente, se exclui pensar o acontecimento como fora, ou como excedente radical em relação a toda causalidade (para se convencer disso, basta lembrar que Foucault não quer aceitar um 'fora' da história)” (REVEL, 2010, p. 96, tradução nossa).

\section{REFERÊNCIAS}

CANDIOTTO, C. 2009. Notas sobre a arqueologia do saber em Les Mots et les choses. Revista de Filosofia Aurora, Curitiba, v. 21, n. 28, p. 13-28.

CANGUILHEM, G. 1970. Muerte del hombre o agotamiento del Cogito? In: BURGELIN, P. et al. Análisis de Michel Foucault. Buenos Aires: Tiempo Contemporaneo. p. 122-147.

CERTEAU, M. 2009. Les sciences humaines et la mort de l'homme. In: ARTIÈRES, P. et al. (Ed.). Les Mots et les choses de Michel Foucault: regards critiques (1966-1968). Caen: Presse Universitaires de Caen. p. 175-197. 
DÁVILA, J.; GROS, F. 1998. Michel Foucault lector de Kant. Mérida: Universidad de Los Andes.

DREYFUS, H. L.; RABINOW, P. 1995. Michel Foucault, uma trajetória filosófica: para além do estruturalismo e da hermenêutica. Rio de Janeiro: Forense Universitária.</bok> e Rabinow (1995)

FOUCAULT, M. 1963. Naissance de la clinique. Paris: Quadriage/Presses Universitaires de France. . 1966. Les Mots et les choses: une archéologie des sciences humaines. Paris: Gallimard. (Coll. Tel.). . 1994a. Réponse à une question. In: FOUCAULT, M. Dits etécrits. Paris: Gallimard. p. 673-695.v. 1. . 1994b. Préface à l'édition anglaise. In: FOUCAULT, M. Dits et écrits. Paris: Gallimard. p. 7-13.v. 2. . 1994c. À propos de la généalogie de l'éthique: un aperçu du travail en cours. In: FOUCAULT, M. Dits et écrits. Paris: Gallimard. p. 609-630. v. 4.

. 2001. Filosofia e literatura. In: MACHADO, R. Foucault, a filosofia e a literatura. 2. ed. Rio de Janeiro: Jorge Zahar. p. 137-174

.2009. Lettre de Michel Foucault du 8 mars 1967. In: ARTIÈRES, P. et al. (Ed.). Les mots et les choses de Michel Foucault: regards critiques 1966-1968. Caen: Presses universitaires de Caen. p. 131-144.

MACHADO, R. 1988. Archéologie et épistémologie. In: CANGUILHEM, G. (Ed.) Michel Foucault Philosophe: rencontre internationale. Paris: Seuil. p. 15-32.

REVEL, J. 2010. Foucault, una pensée du discontinu. Paris: Mille et Une Nuits.

SABOT, P. 2015. Le même et l'ordre: Michel Foucault et le savoir à l'âge classique. Lyon: ENS Éditions.

SARTRE, J.-P. 2009. Jean-Paul Sartre répond. In: ARTIÈRES, P. et al. (Ed.). Les Mots et les Choses de Michel Foucault: regards critiques 1966-1968. Caen: Presses universitaires de Caen. p. 75-89. 